\title{
Promoting Policies that Make Innovation Benefit All: The OECD TIP Group @50
}

\author{
Dominique Guellec, Caroline Paunov* \\ Science and Technology Policy Division, OECD, Paris 75016, France
}

\begin{abstract}
The Conference TIP@50 commemorated the 50th meeting and the 25th Anniversary of the OECD Working Party on Innovation and Technology Policy (TIP). It was an exceptional occasion to take stock of achievements of the TIP since its creation in 1993 and to shape ideas on the future of innovation and technology policy. The following article summarises the main takeaways from the TIP@50 meeting: a systemic approach to innovation policy-making is more important than ever; coordination within government is needed as innovation is mobilised in all policy fields; new quantitative methods offer new avenues for evidence-based policy making; knowledge transfer is important from an economic and societal perspective; getting the policy mix for knowledge transfer between industry and science remains a challenge; policy lessons show effective knowledge transfer needs to integrate several complex dimensions; innovation policies need to contribute more to inclusiveness; inclusive innovation policies allow for wider inclusion in innovation processes; and digitalisation of science and innovation requires changing innovation policies.
\end{abstract}

* Corresponding author at: Caroline.paunov@oecd.org 
Innovation and technology policy has changed substantially over the past decades - some challenges have changed; others remain, but require different policy responses. What have we learnt over the past decades? Where is innovation policy heading?

These were the questions at the heart of the Conference TIP@50 that commemorated the 50th meeting and the 25th Anniversary of the OECD Working Party on Innovation and Technology Policy (TIP). It was an exceptional occasion to take stock of achievements of the TIP since its creation in 1993 and to shape ideas on the future of innovation and technology policy. The event gathered past and present members of the TIP, government representatives, academics, and STI practitioners and leading experts from all OECD countries and other participating countries, including Professor Rongping Mu of the CAS.

The TIP Working Party operates under the OECD Committee for Scientific and Technological Policy (CSTP), founded in 1971, to which China has been a partner since 2001. The CSTP did a Review of innovation policies in China in 2008. The mandate of the CSTP covers policies for science, for bio and nanotechnologies, for innovation (addressed by the TIP) and statistics and indicators. The CSTP publishes well known books like the Science, Technology and Innovation Outlook, the Scoreboard of STI Indicators; it has recently published a report on the Next Production Revolution.

The work of the OECD TIP Working Party and the OECD CSTP in matters of innovation, science and technology policy reflects the mission of the OECD across all policy fields. The OECD (Organisation for Economic Co-operation and Economic Development) is an inter-governmental organisation which gathers 36 countries, from America, Europe, Oceania to Asia (Japan, Korea). The OECD works closely with other countries, notably China, in order to substantiate its motto, "better policies for better lives". The OECD is a platform for government to exchange experience on their policies aiming at enhancing economic growth and well-being. The OECD is a place where governments discuss and converge on particular issues of joint benefit like trade and taxes. The OECD offers statistics, information and policy analysis in all relevant fields, including: macroeconomics, industrial economics, trade, taxes, labor market, education, environment, health - and science and innovation.

The following article summarises the main takeaways from the TIP@50 meeting.

\section{A Systemic Approach to Innovation Policy-making Is More Important than Ever}

Innovation policy-making is more effective by adopting a systemic approach that takes into account the interactions between firms, government, civil society and academia in the innovation ecosystem. Such an approach also needs to consider the combined effects of different innovation policy instruments and how these are shaped by specific regional contexts.

System innovation is a horizontal policy approach to tackle problems that are systemic in nature, such as green growth and inclusive development. Such approach requires engaging with a wide range of stakeholders, from business to academia and different levels of government, in order to set a shared long term vision; developing analytical tools to uncover the causal relations among different elements of the system as well as barriers that hamper stated objectives; and understanding interactions and synergies among different policy areas in order to design holistic policy responses.

The TIP has been helping countries adopt these principles over the past decades, with the development of the National Innovation System approach in the late 1990s and early 2000s, followed by the development of the System innovation and transformation approach to innovation policy. The 
relevance of the system innovation approach today is emphasized with the pressing need of meeting the societal 'grand' or global challenges and the United Nations' Sustainable Development Goals (SDGs).

There is an increasingly important role for innovation policy to foster and co-ordinate knowledge co-creation through open innovation. With more complex innovations that integrate digital components, knowledge producers in industry and academia continue to specialize in specific technology areas and scientific/economic activities. More than ever, innovation thrives from dynamic innovation ecosystems that combine complementary skills of businesses, academia and entrepreneurs.

\section{Coordination Within Government Is Needed as Innovation Is Mobilised in All Policy Fields}

Innovation has become a priority in practically every field of policy, requiring policy co-ordination to optimise policy impacts. Innovation is mobilised in healthcare, education, tax policy etc. all areas of activity businesses and government. This has generated the growing interest in policy circles for "non technological innovation"; it has also created an issue for coordinating the multiple innovation policies conducted in various quarters of government. The issue has two dimensions. One is to transfer lessons learnt in one field to others, so as to make sure that the various government departments follow a similar pattern. The other is coordination of various actions in front of common challenges. Many current challenges (e.g. modernising health, transportation etc.) need innovations of various types, monitored by various departments in government; hence coordination is key to joint success, and a common approach is needed.

\section{New Quantitative Methods Offer New Avenues for Evidence-based Policy Making}

The digital transformation offers new tools for innovation policy analysis. With software developments and increased computing capacities, the possibility to systematically exploit textual information has grown enormously.

The types of data that can be usefully analysed to support STI policy are broad, ranging from official policy papers and evaluations, to administrative data held in government databases, to social media. Such analysis can help identify emerging trends and monitor policy progress over time. However, while semantic analysis holds enormous promise, careful data preparation and exploitation are needed, otherwise results may be misleading.

A TIP workshop was dedicated to semantic analysis for innovation policy, in March 2018, and set the start of the efforts of the TIP to experiment with this approach with the objective to shed further light on its potential for policy analysis.

There were 7 takeaways from the workshop ${ }^{1}$ :

(1) Semantic analysis, a branch of Artificial Intelligence that focuses on extracting meaning from large sets of text, is a fast-growing field that offers huge potential for innovation policy. It allows applying analytical models systematically on a large volume of textual data at a high speed, considering

\footnotetext{
${ }^{1}$ https://www.innovationpolicyplatform.org/system/files/imce/OECD\%20TIP_SemanticAnalysis_summary_FINAL_0.pdf
} 
multi-dimensional parameters at the granular level. It enables the exploration of up-to-date data (e.g. from social media) about specific issues of policy interest, and can help shed light on interactions that go beyond traditional research collaboration indicators.

(2) Semantic analysis techniques allow leveraging new information from large sets of text to inform science, technology and innovation policy. Data sources include traditional ones, such as policy documents, public R\&D funding databases, and patent and publication data; as well as new sources, such as company and university websites with information on ongoing research activities, as well as social media or newspaper articles that capture the public or stakeholders' opinion on STI-related issues.

(3) Semantic analysis provides new insights to characterise innovation ecosystems and detecting technology developments and innovation trends by helping to address questions such as: What are past and emerging research and technology fields? Who is doing what in innovation ecosystems? What are the topics and patterns of collaboration in a specific innovation ecosystem?

(4) Semantic analysis also supports answering questions regarding innovation policy itself. This includes questions such as: How are innovation policy debates evolving over time? How do policy debates relate to academic debates? What innovation policies are in place and what are they supporting? What are the views of the public on specific innovation policy issues?

(5) The right implementation of semantic analysis is needed for the tool to inform policy, requiring the development of guidelines and best practice codebooks. This applies to all stages of analysis, from data selection to data processing and presentation of results. Transparency and replicability of the models used is important. Guidelines and best practice codebooks can help support good quality semantic analyses.

(6) Search and visualisation tools allow leveraging the potential of semantic analysis for innovation policy, by converting the results into valuable information that can be easily used by policy makers. Future efforts are likely to focus on developing more intelligent, user-assisted navigation tools (e.g. diagnostic toolkits).

(7) The adoption of semantic analysis as a policy support tool requires intensive exchange of experiences. Exchanges on good practices, challenges and past failures among policy makers experimenting with their use can help accelerate the successful adoption of semantic analysis in policy. Sharing where possible efforts, for instance, when it comes to building taxonomies in the field of science, technology and innovation can help reduce the costs and time investments.

\section{Knowledge Transfer Is Important from an Economic and Societal Perspective}

The increasing importance of knowledge-based capital for competitiveness, and the high growth potential of many science-based activities reward those countries where firms have access to a strong research base and have the ability to effectively use research findings to innovate.

In an era of tight public budgets, understanding how public research generates the largest impacts on innovation to support growth and address socio-economic challenges becomes ever more important. While a variety of policy instruments are applied to strengthen knowledge sharing between universities and the private sector, evidence on their impacts and interactions is scarce.

In this context, important policy questions arise: How does public research contribute to innovation? What factors promote or hamper such contributions? What are different channels of 
interaction among actors and in what ways do they support innovation? What policy instruments and policy mixes are most appropriate to enhance knowledge sharing? What are emerging challenges and new policy trends in this area?

The TIP has built strong policy expertise in the field of knowledge sharing between science and industry by conducting projects that address these and other related questions.

A key report was published in 2013, Commercialising Public Research: New Trends and Strategies. Public research is the source of many of today's technologies. Public research institutions and universities are also an engine of entrepreneurial ventures from biotech start-ups to Internet giants like Google. Globalisation, open innovation and new forms of venture financing such as crowd funding are changing the way institutions promote the transfer and commercialisation of public researcher results. This report describes recent trends in government and university level policies to enhance the transfer and exploitation of public research. It also showcases, based on case studies of leading institutions in several countries, a number of good practices for increasing the number of university invention disclosures, accelerate licensing contracts and promote open innovation practices between universities and firms.

In September 2016, the TIP organised a High Level Event on the Knowledge Triangle in Paris. The event offered an opportunity for senior government officials and a wide range of stakeholders to share experiences on how to better leverage and integrate the various missions of higher education and public research institutions (i.e. education, research and engagement) in order to increase their contribution to innovation and economic growth. The event marked the end of the TIP project on the knowledge triangle (2015-16) which provided practical insights on the role that education and research funding policies, governance structures, institutional leadership and stakeholder involvement can play in helping higher education and research institutions improve their education, research and thirdmission activities.

\section{Getting Policy Mix for Knowledge Transfer between Industry and Science Remains a Challenge}

The TIP is also investigating the policy mix for knowledge transfer. It is publishing a report which develops an ontology of the policy instruments in place to support science-industry knowledge transfer and offers insights on the policy mix across OECD countries. Adopting a policy mix approach involves placing more attention on the interactions between policy instruments.

The mapping exercise of all relevant policy instruments results in 22 types of policy instruments that are used to support industry-science knowledge transfer in OECD countries. These include, among others, grants for collaborative research; tax incentives for firms that purchase services from universities and public research institutes (PRI); financial support to university spin-offs; mobility schemes for researchers; open access to publicly funded research; networking events and joint roadmapping exercises with the various actors involved in science-industry links.

Policy instruments are classified according to various criteria, including: i) whether they are financial, regulatory or soft instruments; ii) whether they target primarily firms/industry, researchers or universities/PRIs; and iii) the type of knowledge transfer channels being addressed. Other criteria are the supply- or demand-side orientation of policy instruments and their time horizon. 
Most OECD countries make use of similar policy instruments but the ways they design and implement these instruments differ. For instance, during the last decades, most countries have adopted new regulations regarding the ownership of intellectual property (IP) resulting from publicly-funded research, in order to facilitate its commercialisation. However, there are still large differences across countries with respect to the distribution of ownership rights and royalties between the inventor and the institution where the work was conducted. Likewise, most countries have created Technology Transfer Offices (TTOs) to support knowledge transfer, but TTOs differ with respect to their size, institutional configuration and types of functions.

New forms of intervention are also emerging like, for instance, digital platforms to facilitate collaborations or new types of joint labs and intermediary organizations. In particular, new digital platforms facilitate the disclosure of inventions and help to match supply and demand for technology and research inputs by connecting firms with research centres, individual scientists and freelancers.

\section{Policy Lessons Show Effective Knowledge Transfer Needs to Integrate Several Complex Dimensions}

The TIP held a workshop on "boosting knowledge transfer between science and industry" in March 2018, which led to ten "key takeaways"

(1) Platforms play an important role in creating the conditions for knowledge transfer between industry and science. With new opportunities of digital platforms, new opportunities for identifying possible partners and building collaborations are possible. An example is Korea's Patent Commercialisation Platform (PCP) which connects researchers from 24 universities and more than 8000 SMEs. The PCP employs experts that provide advice to SMEs and match SMEs to university technologies to support technology transfer. The PCP also offers follow-up financing for commercialisation of these technologies by SMEs.

(2) Industry-science collaborations are more important than ever in emerging technology fields, such as artificial intelligence and big data analytics. Large firms are collaborating in diverse ways with leading international universities to investigate productivity-enhancing applications of emerging technologies. German company Siemens, for instance, has established Centres of Knowledge Exchange across eight technical universities in order to stay up-to-date in new research fields.

(3) Effective knowledge transfer happens where researchers move frequently between industry and science. This requires building conditions allowing for "revolving door" two-way mobility for researchers to temporarily join industry and for industry researchers to temporarily participate in university activities.

(4) The increased speed of innovation calls for flexible policy instruments. Flexible policy instruments allow for experimentation, and that is characterised by little red tape, low barriers to participate. DARPA-style support schemes are an example of a successful support scheme with these characteristics.

(5) Universities may want to invest more in profiling. Universities may want to invest in those

\footnotetext{
${ }^{2}$ https://www.innovationpolicyplatform.org/system/files/imce/OECD_TIP_knowledge\%20transfer\%20workshop.pdf
} 
research fields where they have a comparative advantage and market those to potential industry partners. As emphasised by industry representatives, such profiling can help them more easily identify which university to turn to for collaborative research. These strategies, however, need to be weighed against the rising importance of multi-disciplinarity and education and basic research roles of universities.

(6) There is no "one-size-fits-all" knowledge transfer policy mix. Policies have to adapt to the type of research institutions and industries. For instance, policies in support of university patenting will be more useful for industries that rely on patented technologies compared to other sectors.

(7) Policy needs better guidance on how to adapt policy instruments to different contexts. The mix of policy instruments in support of knowledge transfer needs to be adapted to different sizes and R\&D capacities of enterprises, as well as types of education and research institutions present in a country and region. This should be done in consultation with local stakeholders from science and business.

(8) Finding the right balance between universities' engagement with industry and focus on basic research is a topic of much policy debate. While the push for universities to engage more with industry may help support innovation, this push may also lead researchers to engage in less risky, less radical projects and to reduce the long-term stock of knowledge for innovation. Whether there is a threat to basic research from more engagement with businesses depends on the countries, regions, institutions and researchers.

(9) New funding models for universities and research intermediaries (with emphasis on profitability) may turn them into competitors of industry rather than "intermediaries". The implications of this development for knowledge transfer need to be critically assessed.

(10) Evaluation matters. Better metrics are called for to capture knowledge transfer and better evidence is needed on the impacts of public research on innovation. This includes in particular capturing better the different channels of knowledge transfer. It also requires understanding crosscountry evidence on impacts of public research to investigate how the economic, institutional and policy context matters for impact.

\section{Innovation Policies Need to Contribute More to Inclusiveness}

Inequalities are one of today's most pressing challenges facing OECD countries. Over the past three decades, income disparities have risen to unprecedented levels, with the richest $10 \%$ in the OECD area earning almost ten times more than the poorest $10 \%$. Wealth today is even more concentrated than income: in 2012, the richest $10 \%$ controlled half of all total household wealth, while the poorest $40 \%$ held only $3 \%$ of the total across 18 OECD countries ${ }^{3}$. People who are economically disadvantaged often also fall behind in other non-income dimensions of well-being. They often have lower educational attainment, are more likely to be unemployed or dissatisfied with their jobs, and report worse health. Certain social groups are persistently overrepresented in the lower end of income distributions, pointing to the nexus

\footnotetext{
${ }^{3}$ The countries in question are Australia, Austria, Belgium, Canada, Finland, France, Germany, Greece, Italy, Korea, Luxembourg, the Netherlands, Norway, Portugal, the Slovak Republic, Spain, the United Kingdom and the United States. In the case of the United Kingdom, the geographical coverage of the data is limited to Great Britain (excluding Northern Ireland).
} 
between economic disadvantage and certain social identity dimensions (such as gender, age, ethnic origin and place of residence).

The particular features of a country's production system also play a central role in shaping inclusive growth. The distribution of capacities and opportunities to participate in innovation activities across firms/sectors (referred to here as industrial inclusiveness) and regions (territorial inclusiveness) might be the most important of these features. The industrial and territorial dimensions are closely linked to social inclusiveness (Fig. 1). When innovation capacities are not widely distributed across sectors and regions, the well-being of individuals working in less innovative sectors and/or living in less innovative regions is affected; they suffer from multiple types of disadvantage (e.g. low skills, low income), as they are less able to move to more innovative activities.

High levels of inequality not only affect the well-being of the most vulnerable segments of the population, but also undermine the performance of economies generally. As those more disadvantaged generally have fewer resources to invest in skills and education, they have fewer opportunities to access more productive and rewarding jobs. Consequently, human resources in the economy are not used to the fullest degree, which negatively affects productivity growth in the long run. In addition, widening income gaps have a negative impact on social cohesion and diminish trust in institutions, which can contribute to social and political instability.

Digital technologies have improved opportunities for consumers to find best products at affordable prices, and have also improved education, health and government services in ways that have favoured social inclusion. Measuring the impacts of such applications has proved difficult, given the largely non-monetary nature of welfare gains associated to digital innovations. Digitalisation has increased the wedge between metrics of production and welfare, reinforcing the need to complement GDP with other indicators such as consumer surplus. In particular, while the production value of free digital products is captured by the underlying financing sources bearing their costs (e.g. advertising and big data), this production value does not reflect the consumer value (or welfare) generated by these products.

Further contributions that emerging digital technologies are making toward inclusive growth include:

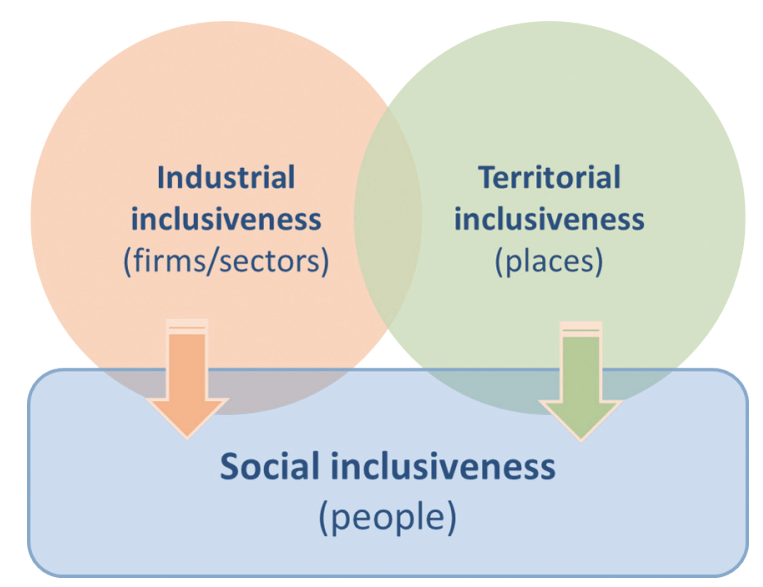

Fig. 1 Interactions among social, industrial and territorial inclusiveness 
- the Internet of Things (IoT) - devices and objects that can be manipulated via the Internet, with or without active human involvement

- big data analytics - a set of techniques used to interpret large volumes of data generated by the increasing digitisation of content, greater monitoring of human activities, and the spread of the IoT

- artificial intelligence (AI) - the ability of machines and systems to acquire and apply knowledge and to carry out intelligent behaviour

- blockchain - a database that enables value transactions within computer networks and without the necessity of a central institution or third party.

Policy makers could leverage the potential of digital innovations further by:

- Incentivising IoT, big data and AI applications in healthcare and education that benefit disadvantaged and excluded groups. Many prospective applications are led by the public sector. For instance, in the IoT this includes not only the development of connected equipment (diagnostic devices) in public hospitals, but also the underlying digital infrastructures (e.g. databases). Potential efficiency gains in healthcare also motivate the consideration of IoT and AI technologies in R\&D and innovation-funding schemes.

- Employing and experimenting with big data tools for policy design and implementation. These tools offer possibilities for gathering information about target groups in disadvantaged conditions; for better tracking of the factors leading to social exclusion; and for monitoring policy implementation.

- Continuing efforts to reduce the digital divide - i.e. narrowing inequalities in access to ICT and disparities in the skills necessary to effectively use these technologies. With regard to Internet access, countries can extend broadband coverage by encouraging investment and competition in the private sector (OECD, 2016b). This also requires ensuring that individuals have adequate skills to leverage opportunities of ICTs.

\section{Inclusive Innovation Policies Allow for Wider Inclusion in Innovation Processes}

Countries are increasingly implementing "inclusive innovation policies" - a specific set of innovation policies that aim to boost the innovation capacities and opportunities of individuals and social groups that are underrepresented in innovation, research and entrepreneurship activities. Their goal is that all segments of society have opportunities to successfully participate in and benefit from innovation (here termed "social inclusiveness").

Innovation policy instruments for inclusive growth can be categorised under three distinct policy objectives: i) fostering the integration of disadvantaged groups in innovative activities; ii) addressing barriers to entrepreneurship encountered by disadvantaged groups; and iii) enhancing innovation in lagging regions (Table 1). These share a common focus on improving the well-being of more disadvantaged groups by connecting them with new opportunities; strengthening their capacities to participate in more productive activities; and reducing social inequalities.

Country experiences in inclusive innovation policies point towards a range of specific implementation challenges that do not apply to the same extent to innovation policies more generally. The OECD's Inclusive Innovation Policy Toolkit is a practical and interactive guide developed to aid policy makers design and implement effective innovation policies for inclusive growth. It provides a set of examples of inclusive innovation policies implemented in different countries. 


\section{The Digitalisation of Science and Innovation Requires Changing Innovation Policies}

The digital transformation is changing the way economies work and innovation is organised. The TIP project 'Digital and Open Innovation' investigates how digital transformation changes the rationales for innovation policy, and what are the most appropriate policy instruments to foster vibrant innovation ecosystems and contribute to sustainable and inclusive growth.

Most innovations today are new products and processes enabled by digital technologies or embodied in data and software. This transformation first took place in digital sectors (e.g. software) but is now much more widespread across all sectors, including in the services (retail, education) and manufacturing (automotive). The "fluidity" of digital innovation (as opposed to tangible innovation) makes it ubiquitous and malleable: A same data or computer code can be used in various places at the same type, can be shared among many users at a distance at little or no cost, can be adapted a little cost to differentiated uses etc. This results in new economic mechanisms, like "scale without mass" (a small company can serve the global market almost instantaneously), "winner take most" market structures (one or a few companies dominate each market), an acceleration of economic processes and

Table 1 Overview of innovation policy approaches to foster inclusiveness

\begin{tabular}{|c|c|c|}
\hline \multicolumn{3}{|c|}{ Inclusive innovation policies to: } \\
\hline $\begin{array}{l}\text { Foster the integration of } \\
\text { disadvantaged groups }\end{array}$ & $\begin{array}{l}\text { Address barriers to } \\
\text { entrepreneurship encountered } \\
\text { by disadvantaged groups }\end{array}$ & $\begin{array}{l}\text { Enhance innovation in } \\
\text { lagging regions }\end{array}$ \\
\hline $\begin{array}{l}\text { Building capacities } \\
\text { - Access to high-quality science } \\
\text { education for disadvantaged groups } \\
\text { - Schemes for communication and } \\
\text { popularisation of S\&T } \\
\text { - Entrepreneurship education } \\
\text { - Grants for researchers from } \\
\text { disadvantaged groups } \\
\text { - Funds to research institutions } \\
\text { for implementing plans to } \\
\text { improve the research environment } \\
\text { for disadvantaged groups } \\
\text { Addressing discrimination and stereotypes } \\
\text { - Campaigns to raise awareness (of } \\
\text { venture capitalists, etc.) of } \\
\text { the business potential of activities } \\
\text { of disadvantaged groups } \\
\text { - Mentoring programmes and } \\
\text { provision of role models to } \\
\text { incentivise disadvantaged groups } \\
\text { Providing incentives to invest in (inclusive) } \\
\text { innovation } \\
\text { - Grants } \\
\text { - Repayable grants }\end{array}$ & $\begin{array}{l}\text { Facilitating access to finance } \\
\text { - Microcredit (micro-loans) } \\
\text { - Equity financing } \\
\text { - Educating in finance } \\
\text { Providing support for business } \\
\text { development } \\
\text { - Information to entrepreneurs } \\
\text { - Coaching and mentoring } \\
\text { - Business counselling/advice to } \\
\text { entrepreneurs } \\
\text { - Assistance to access new markets } \\
\text { - Technology transfer assistance } \\
\text { Promoting networks involving industry, } \\
\text { academia and the financial sector } \\
\text { - Innovation vouchers } \\
\text { - Entrepreneurial networks } \\
\text { Improving access to talent by small } \\
\text { businesses } \\
\text { - Grants to SMEs to recruit researchers/ } \\
\text { experts to implement innovation } \\
\text { projects } \\
\text { - Providing SMEs with access to } \\
\text { specialised online job portals }\end{array}$ & $\begin{array}{l}\text { Accessing global knowledge and } \\
\text { technology } \\
\text { - Demonstration of new technologies } \\
\text { and training by S\&T specialists } \\
\text { - Financial support to projects } \\
\text { that use STI solutions to address } \\
\text { local challenges } \\
\text { Maximising the potential of existing } \\
\text { assets } \\
\text { - Identification of sectors with } \\
\text { potential in a region and training of } \\
\text { potential regional entrepreneurs in } \\
\text { those sectors } \\
\text { - Intellectual property protection } \\
\text { in traditional sectors (e.g. } \\
\text { geographical indications) } \\
\text { - Support for regional governments } \\
\text { to implement STI projects and } \\
\text { develop research capabilities } \\
\text { Attracting innovative firms to peripheral } \\
\text { regions } \\
\text { - Technology parks } \\
\text { - Special economic zones } \\
\text { - Grants for business R\&D in } \\
\text { peripheral regions }\end{array}$ \\
\hline
\end{tabular}


notably innovation (more frequent product updates), servitisation of innovation (products become or are sold as services), strengthened globalisation (national boundaries get less relevant).

These changes are having deep and broad impact on innovation policies. Innovation policies need to take stock of data access issues, with measures favouring access to data while respecting other concerns like intellectual property rights or privacy. Government should promote open science, data sharing among researchers and cooperation between innovators, to adapt competition and intellectual property policy frameworks. Policies need to become more agile, more reactive, otherwise they might lose influence and relevance. Adapting to digitalisation is particularly difficult for small and medium sized entreprises (SMEs), as they lack funds and skills: government might provide them support (access to capital and to skills), while not bailing out firms which are not competitive. Government also need to seize the opportunities offered by digital technologies to better design, monitor and evaluate innovation policies (e.g. setting data bases of researchers connected to publications, patents etc. and exploited with AI software).

\section{Conclusion}

The TIP Working Party has been an influential arena for innovation policy over the past 25 years. It is now focusing its efforts on the most salient issues in the field, notably digitalisation, research funding policies, knowledge sharing, support to business innovation, and innovation of addressing grand challenges. That puts it in the best position to continue being relevant in the coming 25 years. 